\title{
Measurements of the Doppler and multipath spread of HF signals received over a path oriented along the midlatitude trough
}

\author{
E. M. Warrington and A. J. Stocker \\ Department of Engineering, University of Leicester, Leicester, UK
}

Received 10 November 2002; revised 13 May 2003; accepted 28 May 2003; published 5 September 2003.

[1] The presence of the midlatitude trough can severely impact on HF radio systems since the electron density depletion within the trough reduces the maximum frequency which can be reflected by the ionosphere along the great circle path. Furthermore, the associated horizontal gradients in the electron density distribution frequently result in propagation well displaced from the great circle path. The signal characteristics associated with this type of propagation have been investigated for a $1400 \mathrm{~km}$ link oriented along the midlatitude trough between Sweden and the UK. As anticipated, the observed delay and Doppler spread characteristics are strongly dependent upon time of day and season since the trough is a nighttime feature which occurs predominantly during the winter. In particular, the Doppler spread is often large when great circle propagation has been suppressed and reflections are from the north of the great circle path (i.e., from the poleward wall of the trough or from gradients and/or irregularities associated with the auroral zone). INDEX TERMS: 6934 Radio Science: Ionospheric propagation (2487); 6964 Radio Science: Radio wave propagation; 2439 Ionosphere: Ionospheric irregularities; KEYWORDS: ionospheric HF propagation, midlatitude trough

Citation: Warrington, E. M., and A. J. Stocker, Measurements of the Doppler and multipath spread of HF signals received over a path oriented along the midlatitude trough, Radio Sci., 38(5), 1080, doi:10.1029/2002RS002815, 2003.

\section{Introduction}

[2] An important feature of the ionosphere is the midlatitude (subauroral) trough, a region in which the ionospheric electron concentration is depleted by up to an order of magnitude. This region typically has a latitudinal extent of a few degrees, generally occurs at night and is more prominent during the winter and equinoctial months. The trough, which forms at latitudes just below those of the auroral oval, has been investigated by various workers (see, for example, reviews presented by Moffett and Quegan [1983] and Rodger et al. [1992]), and a number of statistical models have been developed [e.g., Halcrow and Nisbet, 1977] which give estimates of the position and extent of the trough as a function of geomagnetic conditions, time of year, etc. More recently, developments in tomography [Mitchell et al., 1997] and observations by EISCAT [Jones et al., 1997] have provided experimental observations of the trough position and structure.

[3] The presence of the midlatitude trough has a severe impact on radio systems operating within the HF band

Copyright 2003 by the American Geophysical Union. 0048-6604/03/2002RS002815\$11.00 since the electron density depletion within this region reduces the maximum frequency which can be reflected by the ionosphere along the great circle path. Gradients in the electron density distribution within the trough walls frequently result in propagation well displaced from the great circle path by several tens of degrees or more [see, e.g., Rogers et al., 1997; Stocker et al., 2000]. From the point of view of this paper, it is noteworthy that the change in propagation mechanism from on-great circle to off-great circle propagation results in changes to the delay and Doppler spreads of the received signals. In particular, the Doppler spread is often large when great circle propagation has been suppressed and reflections are from the north of the great circle path (i.e., from the poleward wall of the trough or from gradients and/or irregularities associated with the auroral zone).

[4] The energetic particle precipitation contributing to the enhancement of electron density on the poleward edge of the trough also creates ionization at $\mathrm{E}$ region altitudes [see Rodger et al., 1992]. Such Sporadic E (Es) is almost always observed under the poleward edge of the trough (90\% of occasions before midnight and $80 \%$ after midnight). On the equatorward edge the occurrence is less, Es being observed on about $75 \%$ of occasions before midnight and 55\% after midnight. Sporadic E 
propagation is therefore also likely at some frequencies over the experimental path. Rodger et al. [1992] also note that there is frequently an offset between the poleward edge of the trough and the equatorward edge of energetic particle precipitation due, it is thought, to the convection of dayside plasma. The ionospheric plasma is fast moving within the trough and poleward of it, and hence significant Doppler effects are imposed on signals reflected within these regions.

[5] Information on multipath delay and Doppler spreading is of importance to designers and operators of digital communication systems within the HF band. When the Doppler and delay spreads exceed system dependent thresholds, the modem performance rapidly deteriorates [Arthur and Maundrell, 1997]. Information on these parameters for various path geometries is therefore important for planning and operational reasons. The ITU, for instance, has recently identified the need for improvements to its propagation prediction models to include delay and Doppler spread parameters, in particular to support broadcasters in their use of the new Digital Radio Mondiale (DRM) standard.

[6] Warrington et al. [1997] presented measurements of the Doppler spreading of signals received over two paths, one contained within the polar cap and one transauroral oval. Measurements of the multipath delay and Doppler spreads observed over several paths within Scandinavia and spanning the auroral zone between Scandinavia and Svalbard, somewhat south of those reported by Warrington et al. [1997], have been presented by Angling et al. [1998]. The aim of this paper is to present results of measurements of a similar type made on a path oriented along the midlatitude trough from southern Sweden to the UK.

\section{Experimental Configuration}

[7] A $1400 \mathrm{~km}$ link along the midlatitude trough (see Figure 1) was established with a transmitter located in Uppsala, Sweden $\left(59.92^{\circ} \mathrm{N}, 17.63^{\circ} \mathrm{E}\right)$ and the receiver in Leicester, UK $\left(52.63^{\circ} \mathrm{N}, 1.08^{\circ} \mathrm{W}\right)$. The transmitter operated on a 3-min cycle during which time transmissions were made in sequence on six frequencies in the range 4 to $18 \mathrm{MHz}$. GPS synchronization was employed to ensure that the transmitter and receiver operations were accurately synchronized. Each transmission comprised a sequence of GPS locked 1667 baud Barker-13 coded BPSK signals. The receiver system was a multichannel DF system capable of measuring the signal characteristics as a function of time of flight (and hence the delay spread could be determined), Doppler frequency, Doppler spread and also direction of arrival. The direction of arrival measurements are of particular importance to other studies undertaken at the University of Leicester and are only used here for diagnostic purposes. In addition, an oblique

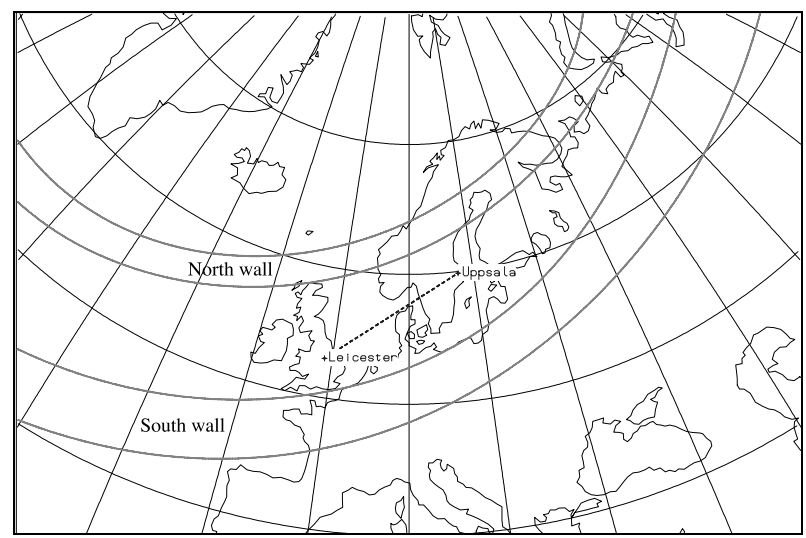

Figure 1. A map showing the propagation path from Uppsala to Leicester. The location of the trough, derived from the model of Halcrow and Nisbet [1977], at 0000 UT on 11 March with $\mathrm{Kp}=3$ is shown, the four lines indicating the outer and inner edges of the two trough walls.

ionospheric sounder was deployed at the sites to provide oblique ionograms to aid interpretation of the measurements. The systems were operated at all times of day over the course of just over a year. Results for the calendar year 2001 are presented here.

\section{Delay and Doppler Spread Parameters}

[8] To aid comparison with those presented from the DAMSON project [see Davies and Cannon, 1993], the multipath and Doppler spread parameters are defined here in a similar manner to that employed by Angling et al. [1998]. The composite multipath spread is a measure of the overall temporal spread of the incoming signal; however, no account is taken of the relative powers contained within the various detected modes. Consequently, measurements have also been included of a parameter, known as the effective multipath spread, which takes the relative modal powers into account and was found to provide better results than the composite multipath spread when employed in modem tests using an HF channel simulator [Angling and Davies, 1999]. The definition of the three spread parameters is as follows:

[9] 1. Composite multipath spread is taken as the temporal separation between the rising edge of the first detected mode and the falling edge of the last detected mode, with a correction applied for the width of the transmitted pulse.

[10] 2. Effective multipath spread is measure of multipath spread which gives a good agreement between the expected modem characteristics and the modem performance under the complex propagation 

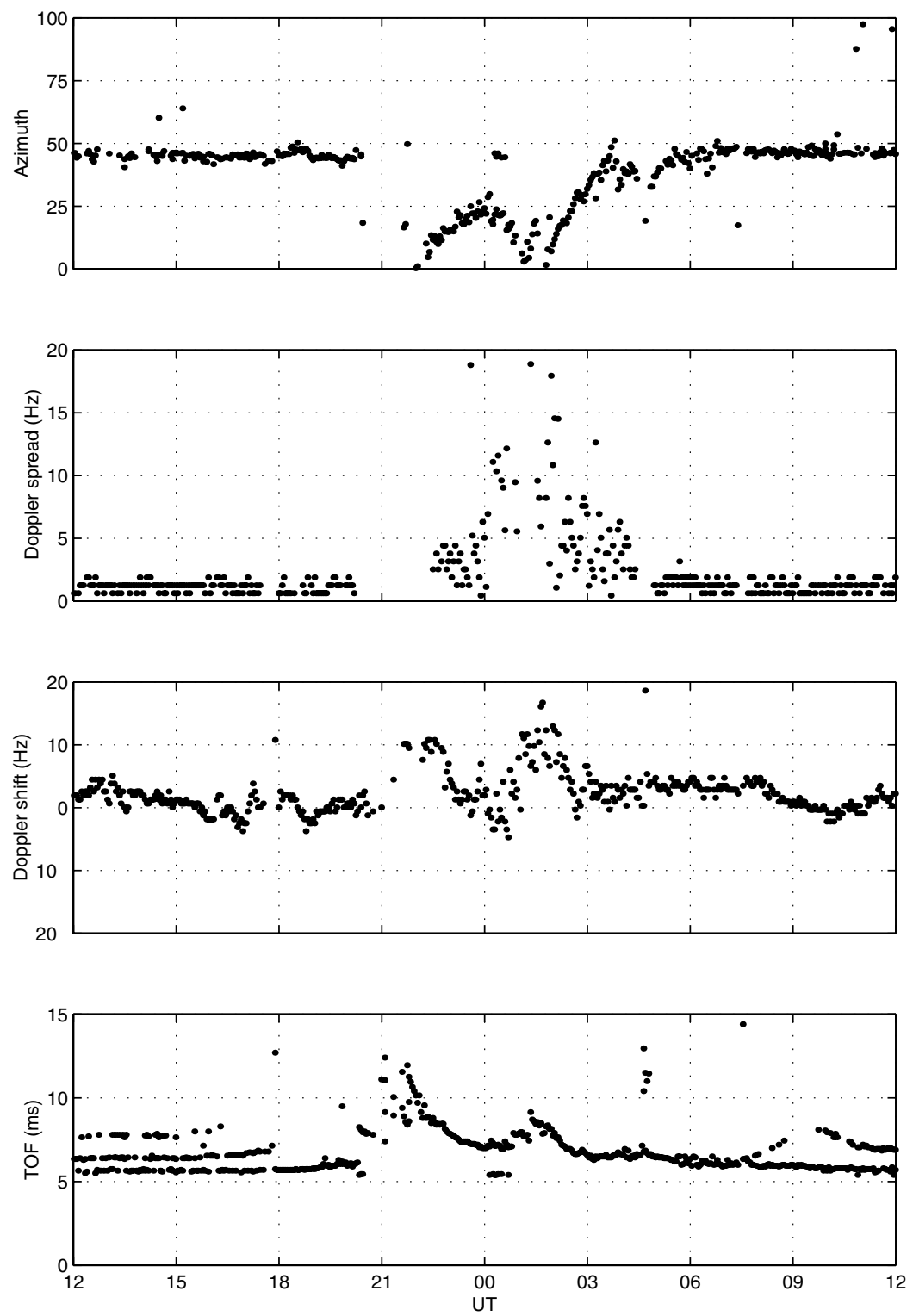

Figure 2. The diurnal variation of direction of arrival, Doppler spread, Doppler shift, and propagation delay for the $11.12 \mathrm{MHz}$ signal from $1200 \mathrm{UT}$ on 31 October to $1200 \mathrm{UT}$ on 1 November 2001.

conditions encountered at high latitudes [Angling and Davies, 1999]. The equivalent multipath spread is calculated for a pair of modes by determining the multipath separation between the rising edge of the central $80 \%$ power region of the first (in delay time) mode and the trailing edge of the central $80 \%$ power region of the last mode (corrected for the transmitted pulse width) and weighting the separation with the ratio of the two modes' total powers. This ratio is always arranged so as to be equal or less than unity. This procedure is applied to each pair of modes in turn and the equivalent multipath spread taken as the maximum value found. If only a single mode is present, then the effective multipath spread is taken to be the mode's $80 \%$ power spread, again corrected for the width of the transmitted pulse.

[11] 3. Composite Doppler spread is defined as the narrowest spectral width containing $80 \%$ of the received signal power. In all cases, a correction is applied for the base noise level. 

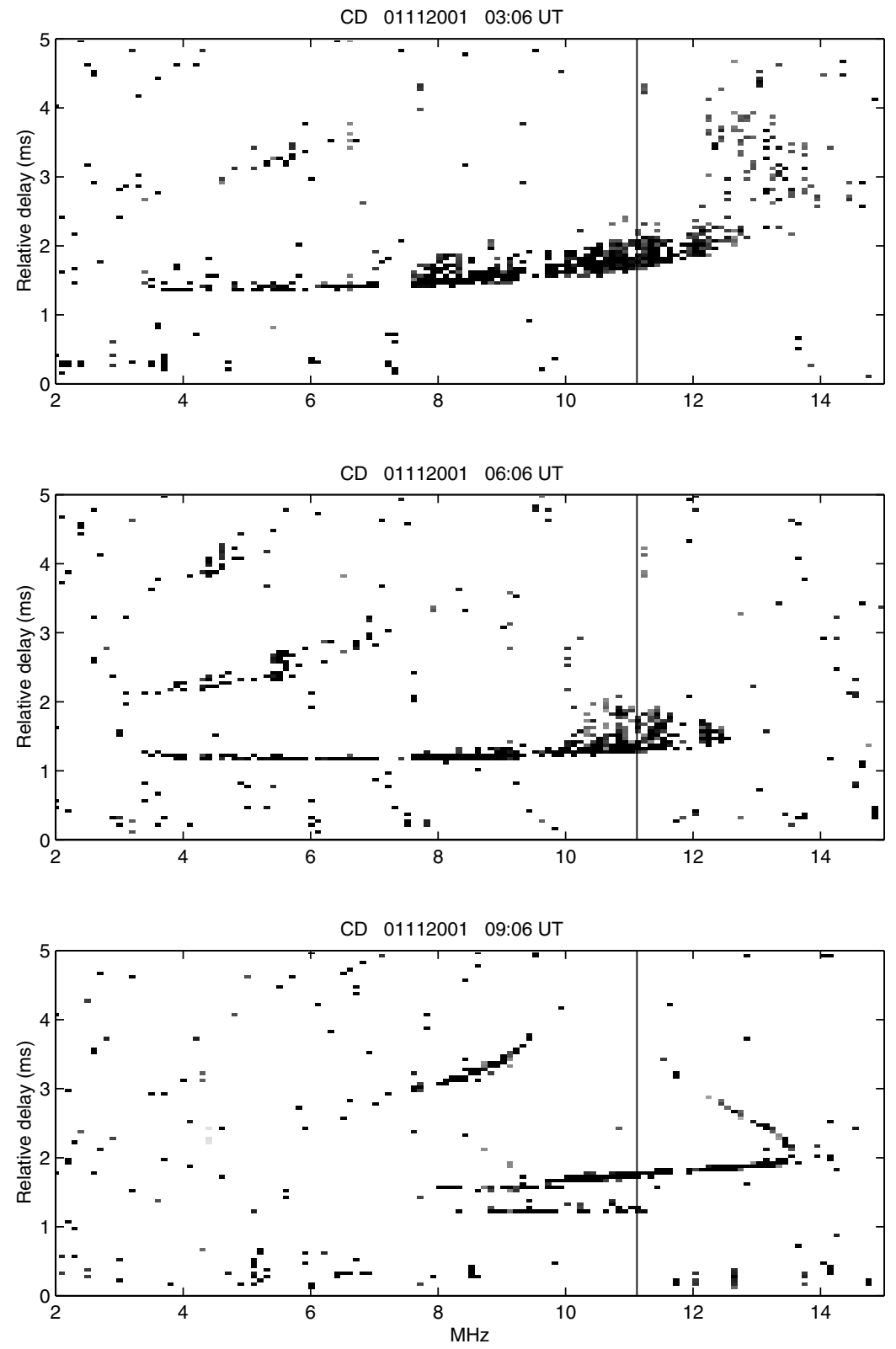

Figure 3. Ionograms for 0306, 0606 and 0906 UT on 1 November 2001.

[12] In performing the analysis presented in this paper, only those points with a SNR of at least $4 \mathrm{~dB}$ were included since the algorithms to determine the spread parameters did not function well at SNRs much below this value. For the purposes of this study (and for consistency with the results presented by Angling et al. [1998]), winter is defined as November, December and January, spring as February, March and April, summer as May, June and July, and autumn as August, September and October. Daytime is considered as the six hour period centered on noon, and nighttime as the six hour period centered on midnight.

\section{Example Measurements Over a 24-Hour Period}

[13] The observations of the deviations of the signal directions of arrival and the oblique ionograms are reminiscent of the bearing deviations attributed to the 

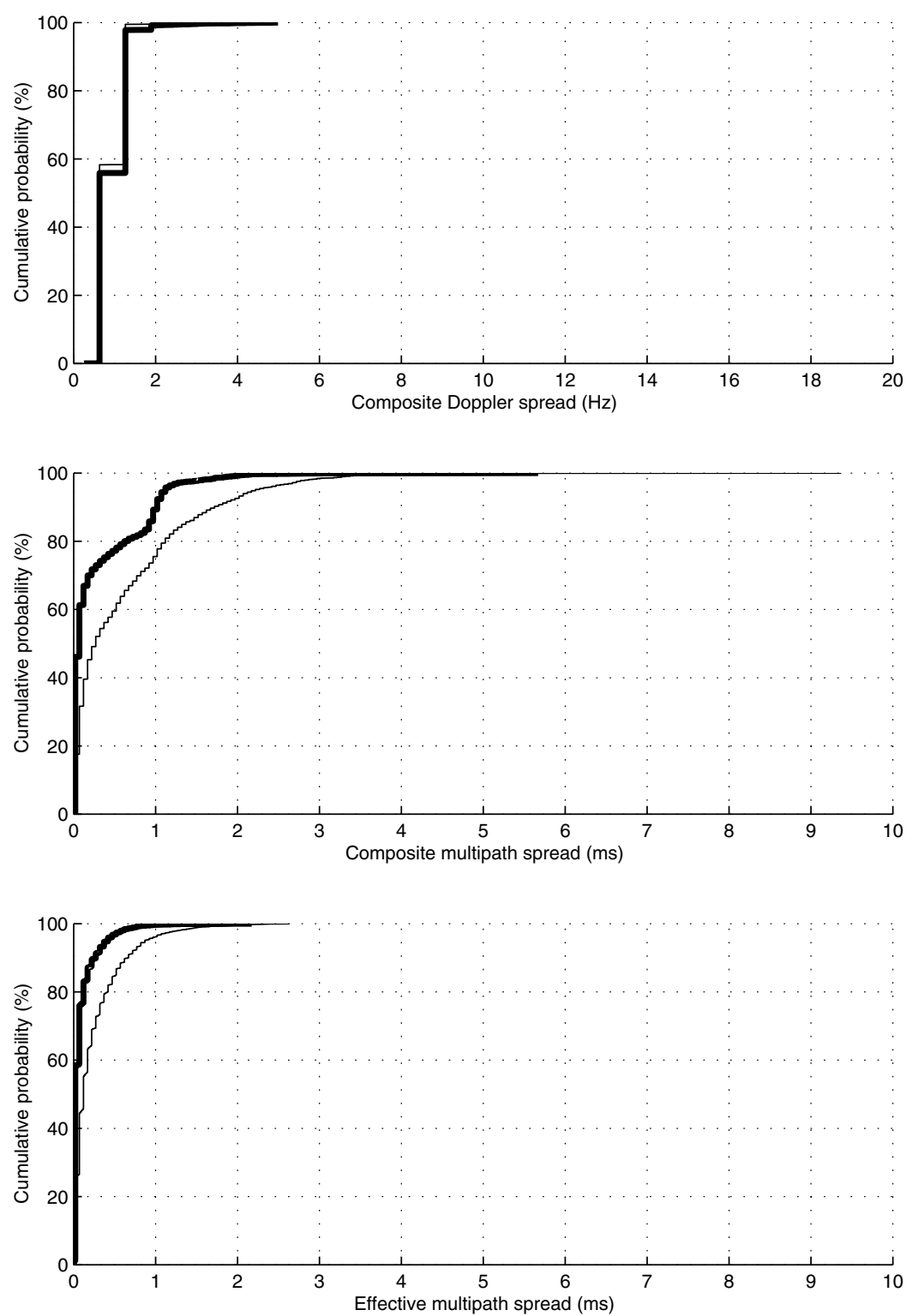

Figure 4. Cumulative probability plots of composite Doppler spread (upper frame), composite multipath spread (middle frame) and effective multipath spread (lower frame) measured at 11.12 $\mathrm{MHz}$ during summer. The bold curves are nighttime and the thin curves for daytime.

presence of the midlatitude trough reported by Rogers et al. [1997] and [2003] for a $910 \mathrm{~km}$ east-west path within Canada. However, unlike these earlier measurements, the nature of the test signals and the receiving equipment enabled the elevation angles of arrival and propagation delays of the individual modes (and hence the multipath delay spreads) to be measured.

[14] An example for the $11.12 \mathrm{MHz}$ signal is presented in Figure 2 which indicates the direction of arrival of the signal (upper frame), the Doppler spread, the Doppler shift and the time of flight (lower frame) of each of the detected propagation modes. Note that a SNR threshold of $4 \mathrm{~dB}$ has been applied to the points displayed in the second frame (Doppler spread) since the estimation accuracy is poor at low SNR values. No such threshold has been applied to the directional estimations, and it is evident that the DF algorithm did not return values on occasions when the SNR was poor. The measurements on 

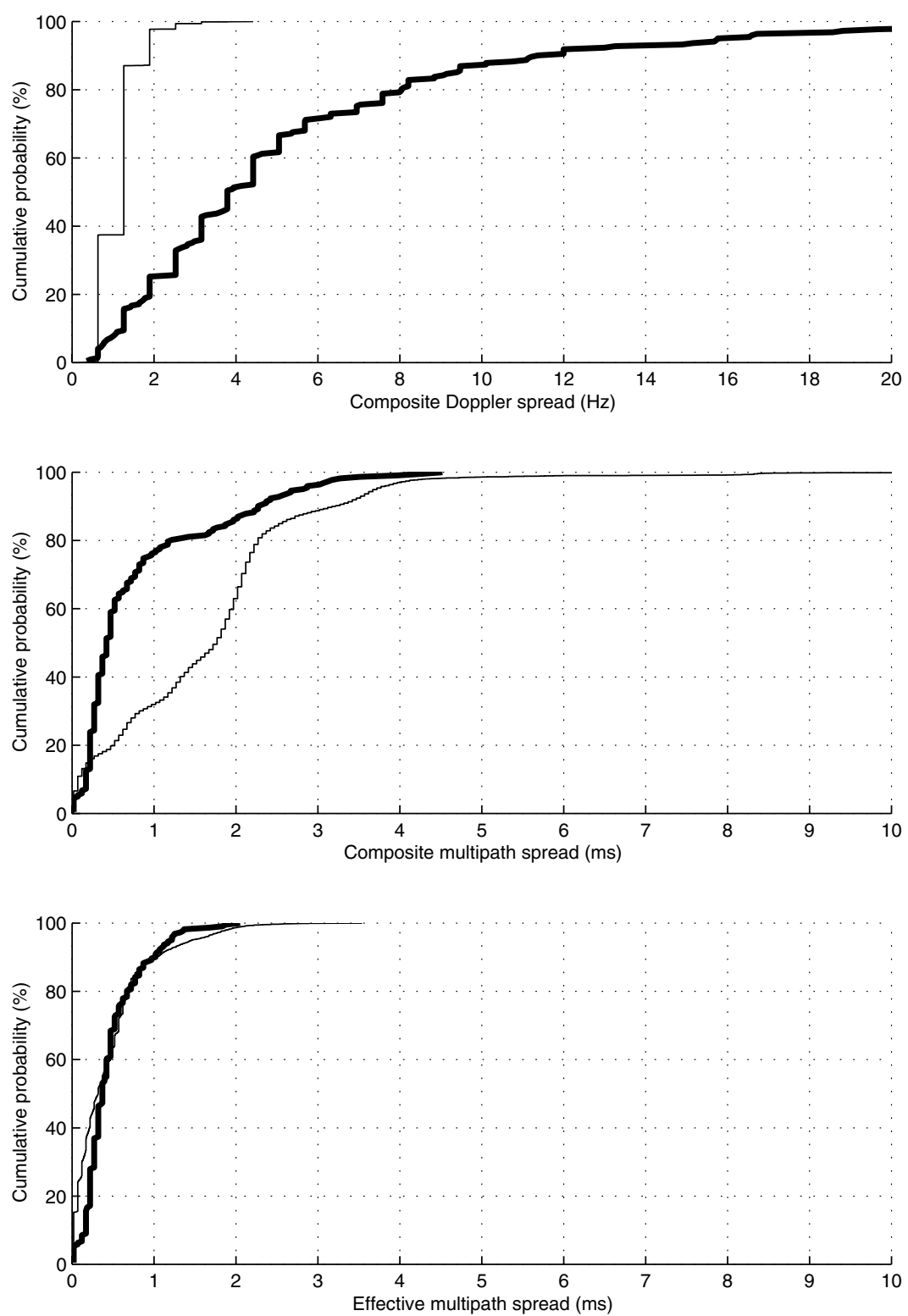

Figure 5. Cumulative probability plots of composite Doppler spread (upper frame), composite multipath spread (middle frame) and effective multipath spread (lower frame) measured at 11.12 MHz during winter. The bold curves are nighttime and the thin curves for daytime.

this frequency are similar to those at $10.39 \mathrm{MHz}$ (unsurprisingly since the frequencies are close) but differ markedly from those obtained at $6.95 \mathrm{MHz}$ where the nighttime SNR was much lower and few measurements of the Doppler spread were possible, and at $14.36 \mathrm{MHz}$ where the SNR was also too low for Doppler spread values to be determined. At the latter frequency, however, it was evident from the time of flight measurements, which were similar to those observed at $11.12 \mathrm{MHz}$, that propagation did occur during the night and that this was likely to have been via a similar northerly path.

[15] Throughout the day propagation is mainly via the $1 \mathrm{~F}$ and $2 \mathrm{~F}$ modes, with some evidence of a $3 \mathrm{~F}$ mode at times. At about 2130 UT, the propagation delay rapidly increases to around $12 \mathrm{~ms}$ and then slowly reduces to values around $7 \mathrm{~ms}$. This delay then remains approximately at this value until around 0530 UT when the normal day-time propagation characteristics return. Of 

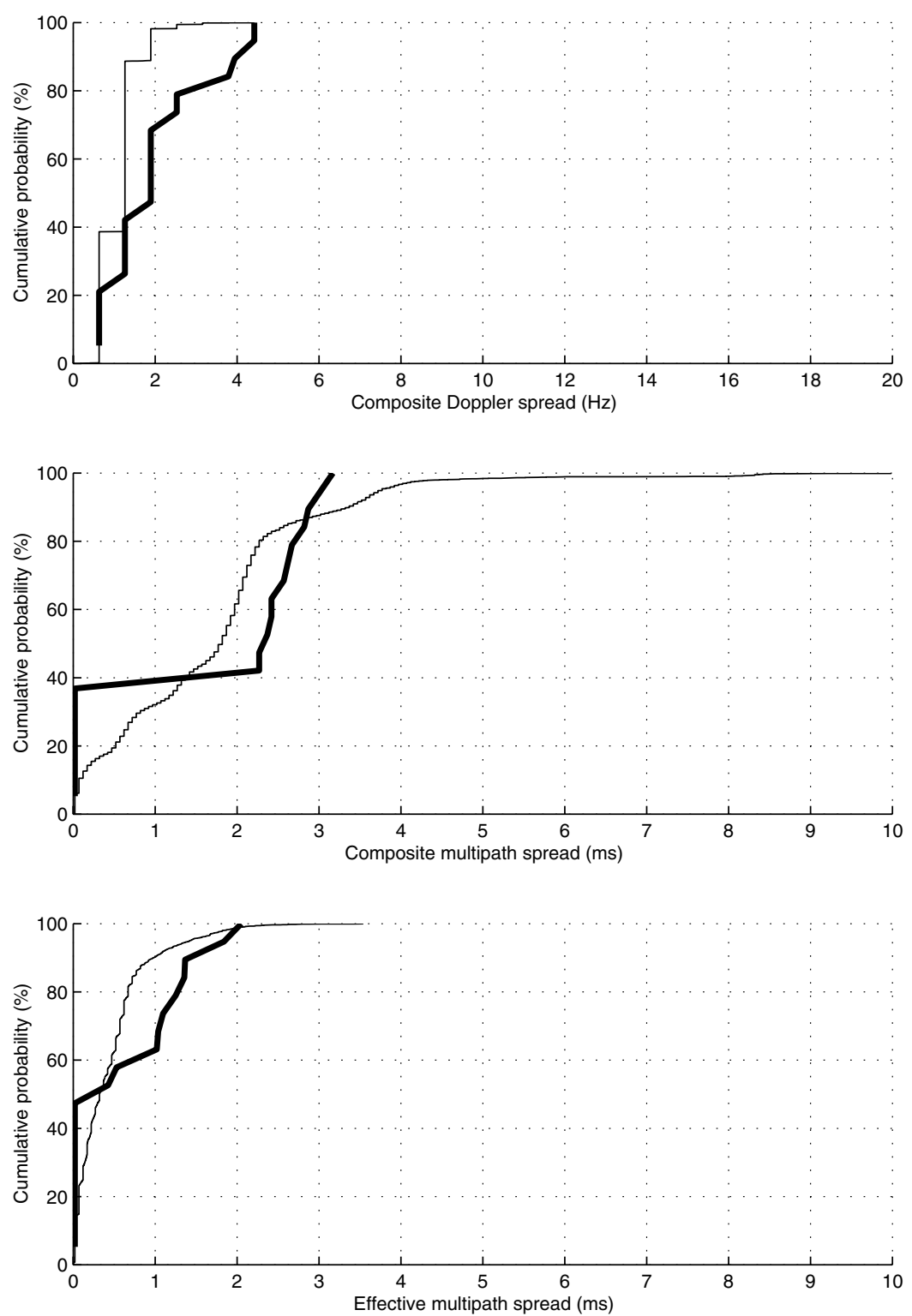

Figure 6. Cumulative probability plots of composite Doppler spread (upper frame), composite multipath spread (middle frame) and effective multipath spread (lower frame) measured at 11.12 $\mathrm{MHz}$ during winter for signals arriving close to the great circle direction. The bold curves are nighttime and the thin curves for daytime.

particular note from the point of view of the topic of this paper is the nighttime period during which the Doppler spreads are significantly greater than during the daytime and propagation is well to the north of the great circle path, characteristics consistent with reflections from auroral irregularities or gradients within the poleward wall of the trough.

[16] Figure 3 shows a sequence of oblique ionograms recorded over the path at 0306 UT on 1 November when propagation is well displaced to the north of the great circle path, at 0606 UT just as propagation is returning to normal daytime conditions, and 0906 UT when propagation has returned to normal daytime conditions. The vertical line on these ionograms indicates a frequency of $11.12 \mathrm{MHz}$, that of the measurements presented in Figure 2. The last ionogram displays the features to be expected of a midlatitude ionogram under undisturbed conditions, whereas the earlier ionograms display spread 

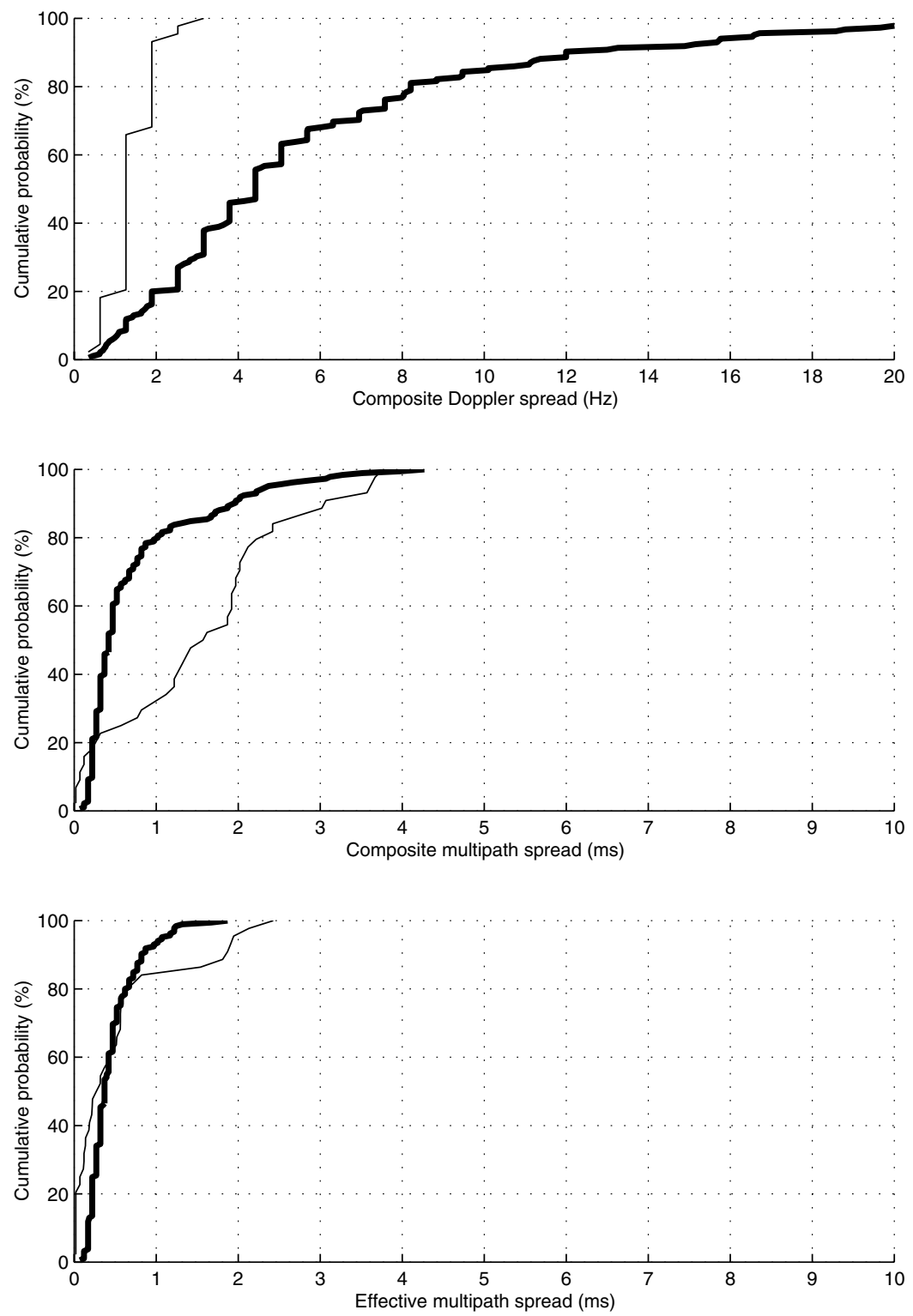

Figure 7. Cumulative probability plots of composite Doppler spread (upper frame), composite multipath spread (middle frame) and effective multipath spread (lower frame) measured at 11.12 MHz during winter for signals arriving well to the north of the great circle direction $\left(<35^{\circ}\right)$. The bold curves are nighttime and the thin curves for daytime.

traces which are indicative of reflections from a diffuse ionosphere.

\section{Observations}

[17] As may be expected, the measured spread characteristics are strongly dependent upon time of day and season since the trough is a nighttime feature which occurs predominantly during the winter. This is illustrated for the $11.12 \mathrm{MHz}$ signal in Figures 4 and 5 for summer and winter, respectively. It is evident from these figures that, at least for frequencies around $11 \mathrm{MHz}$, both the multipath and Doppler spreads are markedly less in summer than in winter. A strong diurnal variation is also apparent.

[18] For the winter period, it is interesting to consider the spread parameters separately for signals arriving close (taken as between $41^{\circ}$ and $48^{\circ}$ measured clock- 
Table 1. Cumulative Distribution of Spreads for All Frequencies During Winter Daytime (0900-1500 UT, November, December and January)

\begin{tabular}{llllllll}
\hline & & \multicolumn{7}{c}{ Frequency, MHz } \\
\cline { 3 - 8 } & & 4.64 & 6.95 & 10.39 & 11.12 & 14.36 & 18.38 \\
\hline \multirow{2}{*}{ Number of samples } & & 0 & 572 & 5881 & 4997 & 3768 & 5746 \\
Doppler & $25 \%$ & - & 0.6 & 0.6 & 0.6 & 0.6 & 0.6 \\
& $50 \%$ & - & 1.3 & 1.3 & 1.3 & 1.3 & 0.6 \\
& $75 \%$ & - & 1.3 & 1.3 & 1.3 & 1.3 & 1.3 \\
Multipath & $90 \%$ & - & 1.3 & 1.9 & 1.9 & 1.3 & 1.3 \\
& $95 \%$ & - & 1.3 & 1.9 & 1.9 & 1.9 & 1.9 \\
& $25 \%$ & - & 0.1 & 0.5 & 0.7 & 0.0 & 0.0 \\
& $50 \%$ & - & 0.9 & 1.5 & 1.8 & 0.7 & 0.0 \\
& $75 \%$ & - & 1.6 & 2.0 & 2.2 & 1.0 & 0.1 \\
& $90 \%$ & - & 2.7 & 2.7 & 3.2 & 1.3 & 1.2 \\
& $95 \%$ & - & 3.1 & 3.4 & 3.7 & 2.1 & 1.5 \\
& $25 \%$ & - & 0.1 & 0.1 & 0.1 & 0.0 & 0.0 \\
& $50 \%$ & - & 0.2 & 0.3 & 0.3 & 0.1 & 0.0 \\
& $75 \%$ & - & 0.4 & 0.6 & 0.6 & 0.5 & 0.1 \\
& $90 \%$ & - & 0.8 & 0.9 & 1.1 & 0.8 & 0.2 \\
& $95 \%$ & - & 1.1 & 1.4 & 1.5 & 0.9 & 0.6 \\
\hline
\end{tabular}

wise from north) to the great circle direction (Figure 6) and for signals arriving well to the north (taken as between $0^{\circ}$ and $35^{\circ}$ ) of the great circle direction (Figure 7). It is clear from these figures that the large Doppler spreads observed at night are associated with propagation to the north of the GCP, i.e., when the signal is reflected from the disturbed ionosphere forming the north wall of the trough or within the auroral

Table 2. Cumulative Distribution of Spreads for All Frequencies During Winter Nighttime (2100-0300 UT, November, December and January)

\begin{tabular}{|c|c|c|c|c|c|c|c|}
\hline & & \multicolumn{6}{|c|}{ Frequency, MHz } \\
\hline & & 4.64 & 6.95 & 10.39 & 11.12 & 14.36 & 18.38 \\
\hline \multicolumn{2}{|l|}{ Number of samples } & 495 & 769 & 232 & 222 & 6 & 6 \\
\hline \multirow[t]{5}{*}{ Doppler } & $25 \%$ & 0.6 & 0.6 & 1.3 & 1.9 & - & - \\
\hline & $50 \%$ & 0.6 & 1.3 & 3.3 & 3.8 & - & - \\
\hline & $75 \%$ & 1.3 & 1.3 & 5.8 & 6.9 & - & - \\
\hline & $90 \%$ & 1.3 & 1.9 & 8.7 & 11.2 & - & - \\
\hline & $95 \%$ & 1.9 & 1.9 & 12.8 & 15.7 & - & - \\
\hline \multirow[t]{5}{*}{ Multipath } & $25 \%$ & 0.0 & 0.0 & 0.2 & 0.3 & - & - \\
\hline & $50 \%$ & 0.1 & 0.1 & 0.3 & 0.4 & - & - \\
\hline & $75 \%$ & 1.1 & 0.3 & 0.8 & 0.9 & - & - \\
\hline & $90 \%$ & 1.8 & 1.1 & 2.0 & 2.3 & - & - \\
\hline & $95 \%$ & 2.6 & 1.5 & 2.6 & 2.7 & - & - \\
\hline \multirow[t]{5}{*}{ Effective multipath } & $25 \%$ & 0.0 & 0.0 & 0.1 & 0.2 & - & - \\
\hline & $50 \%$ & 0.1 & 0.1 & 0.2 & 0.4 & - & - \\
\hline & $75 \%$ & 0.2 & 0.1 & 0.4 & 0.6 & - & - \\
\hline & $90 \%$ & 0.5 & 0.2 & 0.7 & 1.0 & - & - \\
\hline & $95 \%$ & 0.7 & 0.3 & 0.8 & 1.2 & - & - \\
\hline
\end{tabular}

Table 3. Cumulative Distribution of Spreads for All Frequencies During Equinox Daytime (0900-1500 UT, February, March, April, August, September and October)

\begin{tabular}{llllllll}
\hline & & \multicolumn{6}{c}{ Frequency, MHz } \\
\cline { 2 - 8 } & & 4.64 & 6.95 & 10.39 & 11.12 & 14.36 & 18.38 \\
\hline Number of samples & & 0 & 147 & 10822 & 10645 & 9664 & 8128 \\
Doppler & $25 \%$ & - & 0.6 & 0.6 & 0.6 & 0.6 & 0.6 \\
& $50 \%$ & - & 0.6 & 0.6 & 1.3 & 0.6 & 0.6 \\
& $75 \%$ & - & 1.3 & 1.3 & 1.3 & 1.3 & 1.3 \\
Multipath & $90 \%$ & - & 1.3 & 1.3 & 1.3 & 1.3 & 1.3 \\
& $95 \%$ & - & 1.3 & 1.3 & 1.3 & 1.3 & 1.3 \\
& $25 \%$ & - & 0.2 & 0.7 & 0.7 & 0.0 & 0.0 \\
Effective multipathyyyyyyy & $50 \%$ & - & 1.1 & 1.5 & 1.5 & 0.1 & 0.0 \\
& $75 \%$ & - & 2.0 & 2.2 & 2.4 & 1.0 & 0.1 \\
& $90 \%$ & - & 2.7 & 2.8 & 3.1 & 1.3 & 0.5 \\
& $95 \%$ & - & 3.3 & 3.3 & 3.5 & 1.7 & 1.0 \\
& $50 \%$ & - & 0.1 & 0.1 & 0.1 & 0.0 & 0.0 \\
& $50 \%$ & - & 0.2 & 0.3 & 0.3 & 0.1 & 0.0 \\
& $75 \%$ & - & 0.5 & 0.7 & 0.7 & 0.2 & 0.0 \\
& $90 \%$ & - & 0.8 & 1.0 & 1.0 & 0.5 & 0.1 \\
& $95 \%$ & - & 0.9 & 1.3 & 1.4 & 0.8 & 0.2 \\
\hline
\end{tabular}

oval. Tabulated values of the cumulative distributions of the multipath and Doppler spreads measured on each of the six frequencies employed in the experiments for day and nighttime, winter, equinox and summer are presented in Tables 1-6.

[19] The Doppler spread values observed during winter daytime are low, $95 \%$ of all observations being less than $1.9 \mathrm{~Hz}$ (note that the resolution of the system is in the

Table 4. Cumulative Distribution of Spreads for All Frequencies During Equinox Nighttime (2100-0300 UT, February, March, April, August, September and October)

\begin{tabular}{llllllll}
\hline & & \multicolumn{6}{c}{ Frequency, MHz } \\
\cline { 3 - 8 } & & 4.64 & 6.95 & 10.39 & 11.12 & 14.36 & 18.38 \\
\hline Number of samples & & 462 & 4183 & 2285 & 1390 & 34 & 15 \\
Doppler & $25 \%$ & 0.6 & 0.6 & 0.6 & 0.6 & 0.6 & 0.6 \\
& $50 \%$ & 1.3 & 0.6 & 0.6 & 0.6 & 1.3 & 1.3 \\
& $75 \%$ & 1.3 & 1.3 & 1.3 & 1.3 & 1.9 & 1.9 \\
Multipathyyyyyy & $90 \%$ & 1.9 & 1.3 & 1.3 & 1.3 & 1.3 & 2.2 \\
& $95 \%$ & 1.9 & 1.3 & 1.9 & 2.6 & 1.3 & 2.8 \\
& $25 \%$ & 0.1 & 0.0 & 0.0 & 0.0 & 0.0 & 0.0 \\
Effective multipath & $50 \%$ & 1.4 & 0.1 & 0.1 & 0.1 & 0.0 & 0.0 \\
& $75 \%$ & 2.3 & 1.5 & 0.3 & 0.3 & 0.1 & 0.0 \\
& $90 \%$ & 3.3 & 3.4 & 1.0 & 0.9 & 0.1 & 0.0 \\
& $95 \%$ & 3.6 & 5.8 & 1.0 & 1.0 & 0.2 & 0.0 \\
& $25 \%$ & 0.0 & 0.0 & 0.0 & 0.0 & 0.0 & 0.0 \\
& $50 \%$ & 0.1 & 0.0 & 0.0 & 0.1 & 0.0 & 0.0 \\
& $75 \%$ & 0.5 & 0.1 & 0.1 & 0.1 & 0.1 & 0.0 \\
& $90 \%$ & 1.0 & 0.4 & 0.3 & 0.3 & 0.1 & 0.0 \\
& $95 \%$ & 1.1 & 0.7 & 0.4 & 0.5 & 0.1 & 0.0 \\
\hline
\end{tabular}


Table 5. Cumulative Distribution of Spreads for All Frequencies During Summer Daytime (0900-1500 UT, May, June and July)

\begin{tabular}{lccccccl}
\hline & & \multicolumn{6}{c}{ Frequency, MHz } \\
\cline { 2 - 8 } & & 4.64 & 6.95 & 10.39 & 11.12 & 14.36 & 18.38 \\
\hline Number of samples & & 0 & 3 & 4094 & 4348 & 4017 & 1126 \\
Doppler & $25 \%$ & - & - & 0.6 & 0.6 & 0.6 & 0.6 \\
& $50 \%$ & - & - & 0.6 & 0.6 & 0.6 & 0.6 \\
& $75 \%$ & - & - & 1.3 & 1.3 & 1.3 & 1.3 \\
Multipath & $90 \%$ & - & - & 1.3 & 1.3 & 1.3 & 1.3 \\
& $95 \%$ & - & - & 1.3 & 1.3 & 1.3 & 1.3 \\
& $25 \%$ & - & - & 0.1 & 0.1 & 0.0 & 0.0 \\
Effective multipathyyyyyyyy & $50 \%$ & - & - & 0.7 & 0.3 & 0.1 & 0.0 \\
& $75 \%$ & - & - & 1.5 & 1.0 & 0.2 & 0.0 \\
& $90 \%$ & - & - & 2.2 & 1.7 & 0.6 & 0.0 \\
& $95 \%$ & - & - & 2.7 & 2.2 & 1.0 & 0.1 \\
& $50 \%$ & - & - & 0.1 & 0.0 & 0.0 & 0.0 \\
& $75 \%$ & - & - & 0.2 & 0.1 & 0.0 & 0.0 \\
& $90 \%$ & - & - & 0.5 & 0.3 & 0.1 & 0.0 \\
& $95 \%$ & - & - & 1.2 & 0.9 & 0.5 & 0.1 \\
\hline
\end{tabular}

order of $0.6 \mathrm{~Hz}$ and therefore the accuracy of the low value Doppler spread measurements is not high). The composite multipath spreads are higher at the lower frequencies which is to be expected since multimoded propagation is more prevalent at lower frequencies. A similar trend is evident for the effective multipath spreads but, as must be the case, the values are lower than for the composite multipath spreads, the $95 \%$ value peaking at $1.5 \mathrm{~ms}$ at $11.12 \mathrm{MHz}$. No results are presented for 4.64 MHz since the SNR threshold was not exceeded

Table 6. Cumulative Distribution of Spreads for All Frequencies During Summer Nighttime (2100-0300 UT, May, June and July)

\begin{tabular}{|c|c|c|c|c|c|c|c|}
\hline & \multicolumn{6}{|c|}{ Frequency, $\mathrm{MHz}$} \\
\hline & & 4.64 & 6.95 & 10.39 & 11.12 & 14.36 & 18.38 \\
\hline \multicolumn{2}{|l|}{ Number of samples } & 72 & 3256 & 6087 & 4673 & 772 & 19 \\
\hline \multirow[t]{5}{*}{ Doppler } & $25 \%$ & 0.6 & 0.6 & 0.6 & 0.6 & 0.6 & 0.6 \\
\hline & $50 \%$ & 0.6 & 0.6 & 0.6 & 0.6 & 0.6 & 0.6 \\
\hline & $75 \%$ & 1.3 & 1.3 & 1.3 & 1.3 & 1.3 & 1.3 \\
\hline & $90 \%$ & 1.3 & 1.3 & 1.3 & 1.3 & 1.3 & 1.3 \\
\hline & $95 \%$ & 1.3 & 1.3 & 1.3 & 1.3 & 1.3 & 1.3 \\
\hline \multirow[t]{5}{*}{ Multipath } & $25 \%$ & 0.1 & 0.1 & 0.0 & 0.0 & 0.0 & 0.0 \\
\hline & $50 \%$ & 1.0 & 1.4 & 0.0 & 0.1 & 0.0 & 0.0 \\
\hline & $75 \%$ & 1.2 & 2.3 & 0.4 & 0.4 & 0.1 & 0.0 \\
\hline & $90 \%$ & 2.0 & 3.5 & 1.1 & 1.0 & 0.2 & 0.0 \\
\hline & $95 \%$ & 2.6 & 4.1 & 1.5 & 1.1 & 0.9 & 0.1 \\
\hline \multirow[t]{5}{*}{ Effective multipath } & $25 \%$ & 0.0 & 0.0 & 0.0 & 0.0 & 0.0 & 0.0 \\
\hline & $50 \%$ & 0.0 & 0.1 & 0.0 & 0.0 & 0.0 & 0.0 \\
\hline & $75 \%$ & 0.2 & 0.5 & 0.1 & 0.1 & 0.1 & 0.0 \\
\hline & $90 \%$ & 0.3 & 1.0 & 0.3 & 0.3 & 0.1 & 0.0 \\
\hline & $95 \%$ & 0.8 & 1.3 & 0.5 & 0.4 & 0.2 & 0.1 \\
\hline
\end{tabular}

due to daytime absorption in the D-region. The winter nighttime Doppler spread values are higher than the daytime values, this being particularly marked at 10.39 and $11.12 \mathrm{MHz}$ where the $95 \%$ values are 12.8 and 15.7 Hz, respectively. This is consistent with the example presented in Figures 2 and 3 and discussed in the previous section. Too few results to be significant were obtained at 14.36 and $18.38 \mathrm{MHz}$. Much lower values of Doppler spreading were observed during the equinoxes and summer, indeed the $95 \%$ values are all below $2.5 \mathrm{~Hz}$.

\section{Discussion and Concluding Remarks}

[20] It is not the purpose of this paper to discuss the characterization of modem performance in terms of multipath and Doppler spread characteristics - this topic is discussed in some detail by Arthur and Maundrell [1997] and by Angling et al. [1998]. It is, however, useful to note the tolerance levels of various modem waveform implementations in order to relate the measurements of Doppler and multipath delay spreads presented here to the operational needs.

[21] Modems can be characterized (approximately) such as to have threshold values above which the error rate degrades to intolerable levels. This is illustrated in Figure 8 which shows the SNR required to achieve a bit error rate of $10^{-3}$ for a MIL-STD 110A modem operating at 1200 baud (note there may be differences between different implementations of the standard). In this exam-

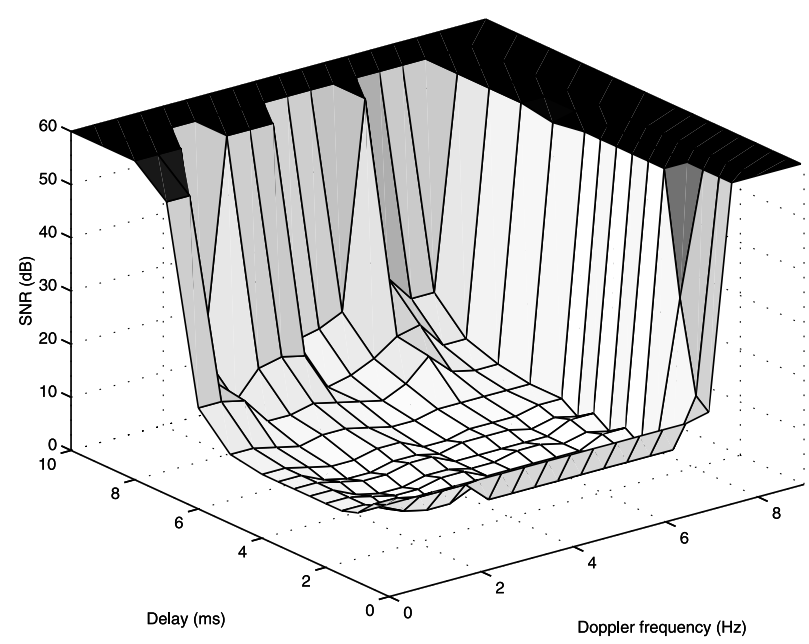

Figure 8. Surface plot of the SNR required to obtain a bit error rate of $10^{-3}$ as a function of delay and Doppler spread for a MIL-STD 110A modem operating at 1200 baud (data supplied by M. J. Angling). Note that the SNR values are capped at $60 \mathrm{~dB}$. The shading is indicative of the SNR value on the vertical axis. 
Table 7. Approximate Levels of Multipath and Doppler Spreads Which Can Be Tolerated for a Range of Modem Waveforms ${ }^{\mathrm{a}}$

\begin{tabular}{lcccc}
\hline $\begin{array}{c}\text { Modem } \\
\text { Waveform }\end{array}$ & $\begin{array}{c}\text { Interleaver } \\
\text { Length }\end{array}$ & $\begin{array}{c}\text { Data } \\
\text { Rate, } \\
\text { bps }\end{array}$ & $\begin{array}{c}\text { Multipath } \\
\text { Tolerance, } \\
\text { ms }\end{array}$ & $\begin{array}{c}\text { Doppler } \\
\text { Tolerance, } \\
\text { Hz }\end{array}$ \\
\hline FSK & & 75 & 5.0 & 40.0 \\
FSK & & 300 & 3.0 & 14.0 \\
FSK & & 600 & 1.0 & 2.0 \\
STANAG 4285 & L & 75 & 6.0 & 32.0 \\
STANAG 4285 & $\mathrm{S}$ & 75 & 6.0 & 28.0 \\
STANAG 4285 & L & 300 & 5.0 & 20.0 \\
STANAG 4285 & $\mathrm{S}$ & 300 & 5.0 & 18.0 \\
STANAG 4285 & $\mathrm{L}$ & 1200 & 5.0 & 10.0 \\
STANAG 4285 & $\mathrm{S}$ & 1200 & 5.0 & 8.0 \\
STANAG 4285 & $\mathrm{L}$ & 2400 & 5.0 & 4.0 \\
STANAG 4285 & $\mathrm{S}$ & 2400 & 5.0 & 4.0 \\
MIL-STD-188-110B & VL & 3200 & 5.0 & 3.5 \\
MIL-STD-188-110B & VS & 3200 & 5.0 & 2.5 \\
MIL-STD-188-110B & VL & 4800 & 4.0 & 3.0 \\
MIL-STD-188-110B & VS & 4800 & 4.0 & 2.0 \\
MIL-STD-188-110B & VL & 6400 & 4.0 & 2.5 \\
MIL-STD-188-110B & VS & 6400 & 4.0 & 1.5 \\
MIL-STD-188-110B & VL & 8000 & 4.0 & 2.0 \\
MIL-STD-188-110B & VS & 8000 & 4.0 & 1.0 \\
MIL-STD-188-110B & VL & 9600 & 4.0 & 2.0 \\
MIL-STD-188-110B & VS & 9600 & 3.5 & 0.5 \\
\hline
\end{tabular}

${ }^{\mathrm{a}}$ From Brown [2001]. The interleaver length refers to options available within the standard: very short (VS), short (S), long (L) and very long (VL).

ple, the modem can (approximately) tolerate Doppler spreads of up to $7 \mathrm{~Hz}$ and multipath spreads of up to $7 \mathrm{~ms}$. Typical values of multipath and Doppler spread values above which performance will not be satisfactory for a number of modem waveforms are presented in Table 7. Unsurprisingly, the higher speed modems are less tolerant of channel dispersion than the lower speed waveforms - the challenge to modem designers is to achieve high data rates with techniques which can tolerate the levels of channel dispersion which frequently occur over HF paths.

[22] It is evident from comparison of the experimental results and the modem tolerance table that the levels of Doppler spreading occurring on the higher frequencies during the night in winter are significant compared to the modem tolerance levelsmdash;difficulties in operating modems at speeds of 1200 baud and above will be prevalent. It is interesting to note, however, that reducing the operating frequency will overcome this particular problem since the Doppler spreads are lower on frequencies where propagation is via the conventional on-great circle propagation mechanism. However, it is often not possible to reduce the operating frequency during the night as the interference levels may become too high.

[23] It is interesting to compare the results presented here with earlier measurements made over a polar cap path and a path crossing the auroral oval presented by Warrington et al. [1997]. These earlier measurements differ from those presented in this paper since only Doppler spread was considered. The metric used was also different - this was referred to as the Doppler Spread Index (DSI) and is a multiple of the area contained under the amplitude spectrum with a correction applied for the base noise level. For comparison purposes, if the shape of the Doppler spectrum is assumed to be gaussian, then the $80 \%$ power width (the metric employed here) is given as DSI/13.82. This conversion has been applied in the following discussion. For full details of these earlier measurements, the reader is referred to the original paper, but to briefly summarize:

[24] 1. Measurements were made over a $1345 \mathrm{~km}$ polar cap path from Clyde River to Alert. During the summer, when the path is illuminated for 24 hours per day, the $90 \%$ cumulative distribution Doppler spread values were typically around $3 \mathrm{~Hz}$. In winter, when the path is in total darkness, there was evidence of the Doppler spread increasing with frequency with $90 \%$ values in the range 6 to $8 \mathrm{~Hz}$.

[25] 2. Measurments were made over a $2955 \mathrm{~km}$ transauroral oval path from Clyde River to Prudhoe Bay. In summer, when the second two hop reflection point was within the auroral oval, typical 90\% Doppler spreads of around $9.5 \mathrm{~Hz}$ were observed. At times when the path geometry was such that the reflection points were outside the expected oval position, the $90 \%$ Doppler spreads were lower, averaging around $6.5 \mathrm{~Hz}$. The Doppler spread tended to decrease with frequency and this may be a result of the increased tendency for multihop propagation at the lower frequencies with the increased likelihood of a reflection point within the oval. In winter, the $90 \%$ Doppler spreads were higher, around $10 \mathrm{~Hz}$, with no marked difference between those times when the reflection points were expected to be within or outside the auroral oval. It is interesting to note that the winter nighttime values of Doppler spread observed over the Uppsala to Leicester path at times when the signal was deviated to the north of the great circle path are similar to those observed over the Clyde River to Prudhoe Bay path when the reflection point was within the auroral oval.

[26] The results presented in this paper illustrate the importance of taking off-great circle propagation effects into account when planning and operating HF radio links. Often, these effects are considered as only being of importance in radiolocation (HF-DF) where deviations from the great circle path result in significant (sometimes intercontinental) triangulation errors. However, it is clear for the path geometry considered in this paper that when great circle propagation is not supported, and the signals propagate via reflections from the north wall of the trough, the signal characteristics differ significantly from those associated with great circle propagation. 
[27] Acknowledgments. The authors would like to thank the Swedish Meteorological Institute for hosting the transmitter at their Marsta site. This investigation is supported by a grant from the EPSRC.

\section{References}

Angling, M. J., and N. C. Davies, An assessment of a new ionospheric channel model driven by measurements of multipath and Doppler spread, paper presented at Colloquium on Frequency Selection and Management Techniques for HF Communications, Inst. of Electr. Eng., 2930 March 1999.

Angling, M. J., P. S. Cannon, N. C. Davies, T. J. Willink, V. Jodalen, and B. Lundborg, Measurements of Doppler and multipath spread on oblique high latitude HF paths and their use in characterizing data modem performance, Radio Sci., 33(1), 97-107, 1998.

Arthur, P. C., and M. J. Maundrell, Multidimensional HF modem performance characteristics, paper presented at Seventh International Conference on HF Radio Systems and Techniques, Inst. of Electr. Eng., 1997.

Brown, D. J., Link maintenance and channel evaluation techniques for HF radiocommunication links, Ph.D. thesis, Univ. of Leicester, Leicester, UK, 2001.

Davies, N. C., and P. S. Cannon, DAMSON-A system to measure multipath dispersion, Doppler spread and Doppler shift on a multi-mechanism communications channels, paper presented at EPP Symposium on Multiple Mechanism Propagation Paths: Their Characterisation and Influence on System Design, Adv. Group for Aerosp. Res. and Dev., Rotterdam, Netherlands, Oct. 1993.

Halcrow, B. W., and J. S. Nisbet, A model of the F2 peak electron density in the main trough region of the ionosphere, Radio Sci., 12, 815-820, 1977.

Jones, D. G., I. K. Walker, and L. Kersley, Structure of the poleward wall of the trough and the inclination of the geo- magnetic field above the EISCAT radar, Ann. Geophys., 15, 740-746, 1997.

Mitchell, C. N., L. Kersley, and S. E. Pryse, The effects of receiver location in two-station experimental ionospheric tomography, J. Atmos. Sol. Terr. Phys., 59, 1411-1415, 1997.

Moffett, R. J., and S. Quegan, The mid-latitude trough in electron concentration of the ionospheric F-layer: A review of observations and modelling, J. Atmos. Terr. Phys., 45, 315343, 1983.

Rodger, A. S., R. J. Moffett, and S. Quegan, The role of ion drift in the formation of ionisation troughs in the mid- and high-latitude ionosphere - A review, J. Atmos. Terr. Phys., 54(1), 1-30, 1992.

Rogers, N. C., E. M. Warrington, and T. B. Jones, Large $\mathrm{HF}$ bearing errors for propagation paths tangential to the auroral oval, IEE Proc. Microwaves Antennas Propag., 144(2), 91-96, 1997.

Rogers, N. C., E. M. Warrington, and T. B. Jones, Oblique ionogram features associated with off-great circle hf propagation at high and sub-auroral latitudes, IEE Proc. Microwaves Antennas Propag., in press, 2003.

Stocker, A. J., E. M. Warrington, and T. B. Jones, Directions of arrival at three frequencies on a propagation path along the mid-latitude trough: A comparison of observations with ray tracing simulations, paper presented at Eighth International Conference on HF Systems and Techniques, Inst. of Electr. Eng., 10-13 July 2000.

Warrington, E. M., T. B. Jones, and B. S. Dhanda, Observations of the Doppler spread on HF signals propagating over high latitude paths, IEE Proc. Microwaves Antennas Propag., 144(4), 215-220, 1997.

A. J. Stocker and E. M. Warrington, Department of Engineering, University of Leicester, Leicester LE1 7RH, UK. (emw@leicester.ac.uk) 